\title{
TESTING THE STANDARDIZED GROWTH CURVE (SGC) TO OSL DATING COASTAL SEDIMENTS FROM THE SOUTH BOHAI SEA, CHINA
}

\author{
GUANG-QUAN CHEN ${ }^{1,2}$, LIANG YI ${ }^{3}$, XING-YONG XU ${ }^{2}$, HONG-JUN YU ${ }^{2}$, JIAN-RONG CAO ${ }^{2,5}$, QIAO SU ${ }^{2}$, \\ LIN-HAI YANG ${ }^{4}$, YONG-HANG XU ${ }^{6}$, JUN-YI GE $^{7}$, ZHONG-PING LAI $^{4}$

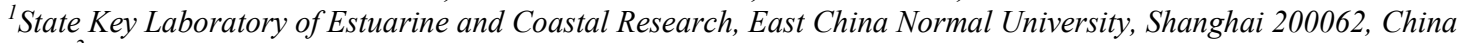 \\ ${ }^{2}$ Key Laboratory of Marine Sedimentology and Environmental Geology, First Institute of Oceanography, \\ State Oceanic Administration, Qingdao 266061, China \\ ${ }^{3}$ State Key Laboratory of Lithospheric Evolution, Institute of Geology and Geophysics, Chinese Academy of Sciences, \\ Beijing 100029, China \\ ${ }^{4}$ State Key Laboratory of Cryosphere Sciences, Cold and Arid Regions Environment and Engineering Research Institute, \\ Chinese Academy of Sciences, Lanzhou 730000, China \\ ${ }^{5}$ College of Environment and Planning, Liaocheng University, Liaocheng 252059, China \\ ${ }^{6}$ Open Laboratory of Ocean \& Coast Environmental Geology, Third Institute of Oceanography, State Oceanic Administration, \\ Xiamen 361005, China \\ ${ }^{7}$ The Laboratory of Human Evolution, Institute of Vertebrate Palaeontology and Palaeoanthropology, Chinese Academy of Sciences,
} Beijing 100044, China

Received 11 May $2012 \quad$ Accepted 21 January 2013

\begin{abstract}
It has been suggested that the standardized growth curve (SGC) method can be used to accurately determinate equivalent dose $\left(D_{e}\right)$ and reduce measurement time. However, different opinions regarding the applicability of the SGC method exist. In this paper, we evaluated quartz OSL SGCs of marine and coastal sediments of different grain sizes and different cores in the south Bohai Sea in China, and tested their applicability to the determination of $\mathrm{D}_{\mathrm{e}}$ values. Our results suggested as follows: (1) The SGC method is applicable to both multiple- and single- aliquot regenerative-dose (MAR and SAR) protocols of OSL dating and efficiently provides reliable estimates of $\mathrm{D}_{\mathrm{e}}$. (2) Finesand quartz of different palaeodoses showed highly similar dose-response curves and an SGC was developed, but old samples using the SGC method have large uncertainties. (3) For coarse-silt quartz, two different types of dose-response curves were recorded: low-dose $(\leq 60 \mathrm{~Gy})$ and high-dose ( $\geq 100 \mathrm{~Gy}$ ). The growth curves of low-dose quartz were similar to each other, facilitating the use of $\mathrm{SGC}$ in $\mathrm{D}_{\mathrm{e}}$ estimations, but errors tended to be larger than those obtained in the SAR method. For high-dose (100-300Gy) quartz, the SGC was also found to be reliable, but there was large uncertainty in $\mathrm{D}_{\mathrm{e}}(>300 \mathrm{~Gy})$ estimation. We suggest that SGC could be employed for the dating of marine and coastal sediments dating using either MAR or SAR OSL protocol and either fine-silt, coarse-silt or fine-sand quartz.
\end{abstract}

Keywords: Standardized growth curve (SGC), OSL dating, marine sediments, Bohai Sea in China.

Corresponding author: L. Yi

e-mail: yi.liang82@gmail.com

ISSN 1897-1695 (online), 1733-8387 (print)

C 2013 Silesian University of Technology, Gliwice, Poland.

All rights reserved. 


\section{INTRODUCTION}

Coastal areas are some of the world's most populated and dynamic landscapes on Earth. Understanding their formation and assessing the past, present, and future impact of change in their geological evolution of our coasts requires reliable chronological tools. The potential and desirability of luminescence dating methods in the determination of the magnitude and timing of events recorded by coastal deposits have long been recognized (see a reviews by Jacobs, 2008), but the lack of precision and the uncertainties in application have prevented them from making breakthrough contributions to various issues (e.g. Murray and Olley, 2002). Recent progress in both methodology and technology now allows demonstration and explicit testing of the reliability of the calculations, making luminescence dating a very attractive and increasingly used approach.

Standardized growth curve (SGC) in optically stimulated luminescence (OSL) dating was first proposed by Roberts and Duller (2004), as a means of accurately estimating equivalent dose $\left(D_{e}\right)$ through a simplified procedure and thus speeding up the measurement process. When SGC is used in a single aliquot regenerative-dose (SAR) protocol (Murray and Wintle, 2000), the SGC of a sample can be determined based only on measurements of natural luminescence signal intensity $\left(\mathrm{L}_{\mathrm{n}}\right)$ and its response to artificial irradiation dose $\left(\mathrm{T}_{\mathrm{n}}\right)$ which speeds up the OSL dating process considerably (Roberts and Duller, 2004). The applicability of SGC has since been tested in sediments from agricultural areas (e.g. Burbidge et al., 2004), loess and desert (e.g. Lai, 2006; Lai et al., 2007; Stevens et al., 2007; Yang et al., 2011; Kang et al., 2012), floodplains (e.g. Shen and Mauz, 2011); coastal dunes (e.g. Telfer et al., 2008), and lacustrine deposits (e.g. Long et al., 2010).

These studies have provided various perspectives on the applicability SGC to OSL dating. Lai et al. (2007) proposed that a universal SGC for different continental loesses exists only when $D_{e}$ is lower than 200 Gy. Although good consistency was observed, the contamination of heavy minerals in loess samples (Lai et al., 2007) or feldspar in lacustrine samples (Long et al., 2010) should be considered carefully during an SGC application. Telfer et al. (2008) reported that the SGC is a regionally based method and only performs well when determining low $(<50 \mathrm{~Gy}) \mathrm{D}_{\mathrm{e}}$ values. It has also been reported that the SGC approach is valid only when an SGC is constructed and applied to samples from the same section in Chinese loess (Stevens et al., 2007) or pottery pieces (Hong and Choi, 2008). As a conservative position, Lai (2006) reported various performances for young $(<270 \mathrm{ka})$ and old samples of Chinese loess, and Yang et al. (2011) constructed two SGCs for desert samples with low ( $<80 \mathrm{~Gy})$ and high $\mathrm{D}_{\mathrm{e}}$ values collected from northern China. From these works, it can be concluded that SGC is applicable to the determination of $D_{e}$ in rapid OSL measurements, but its performance varies by sample type and study area. So far, little attention has been paid to marine and coastal sediments.

Recently, luminescence dating has been widely applied to palaeoenvironmental studies around the Bohai Sea, China. These include assessments of tectonic activity (e.g. Xu et al., 2005), alternations between transgression and regression (e.g. Chen et al., 2008; Yi et al., 2012a), environmental reconstructions (e.g. Han, 2001; Yi et al., 2012b) and human activities (e.g. Zhang et al., 2010). However, the parameters of the existing SGCs varied with the types of sediment and continents, and large offset was observed when previous results were used in estimating $D_{\mathrm{e}} \mathrm{s}$ of sediments collected from the Bohai Sea, suggesting different OSL characteristics of quartz of this type sediment or of this area. Thus, it is necessary to assess the performance of the SGC method in determining the luminescence characteristics of coastal sediments. In this paper, we focus on the applicability of the SGC method to OSL dating using marine and coastal sediments believed to date to the late Pleistocene. The samples used in this study were collected from three boreholes drilled in the south Bohai Sea, China. The test of applicability was conducted from internal comparison to external comparison across sections. Three general SGCs were obtained for quartzes of various grain sizes.

\section{MATERIALS AND MEASUREMENT TECH- NIQUES}

\section{Regional settings}

The south Bohai Sea (Laizhou Bay, Fig. 1) is located between branches of the Yi-Shu Rift (Gao et al., 1980; Zhang et al., 2003). The period from the Neogene to the present has been marked by tectonic quiescence and stable sedimentation rate (Wu et al., 2006; Yu et al., 2008). Sedimentary alternations were mainly between delta, estuarine and tidal plain systems (Xue and Ding, 2008). During regressions, the exposed area of the south Bohai Sea would have been replaced in part by diluvial fan (Chen et al., 1991), loess/sandy dune (Chen et al., 1991; Zhao, 1991, 1995; Yu et al., 1999) or alluvial fan (Meng et al., 1999). The drainage system contains Xiaoqinghe River, Mihe River and Weihe River, which all originate from the Luzhong Mountain Range with several hundreds of kilometres.

\section{Samples for OSL dating}

Samples from shallow sea to deltaic environments for OSL dating were collected from three boreholes, i.e. Lz908, BH1 and BH2, drilled in the south Bohai Sea by First Institute of Oceanography, State Oceanic Administration, China. Borehole Lz908 $\left(37^{\circ} 09^{\prime} \mathrm{N}, 118^{\circ} 58^{\prime} \mathrm{E}\right.$, elevation $6 \mathrm{~m}$ ) was drilled in the summer of 2007. The drilling location was covered by seawater until the middle of last century. The core's length is $101.3 \mathrm{~m}$ with a diam- 


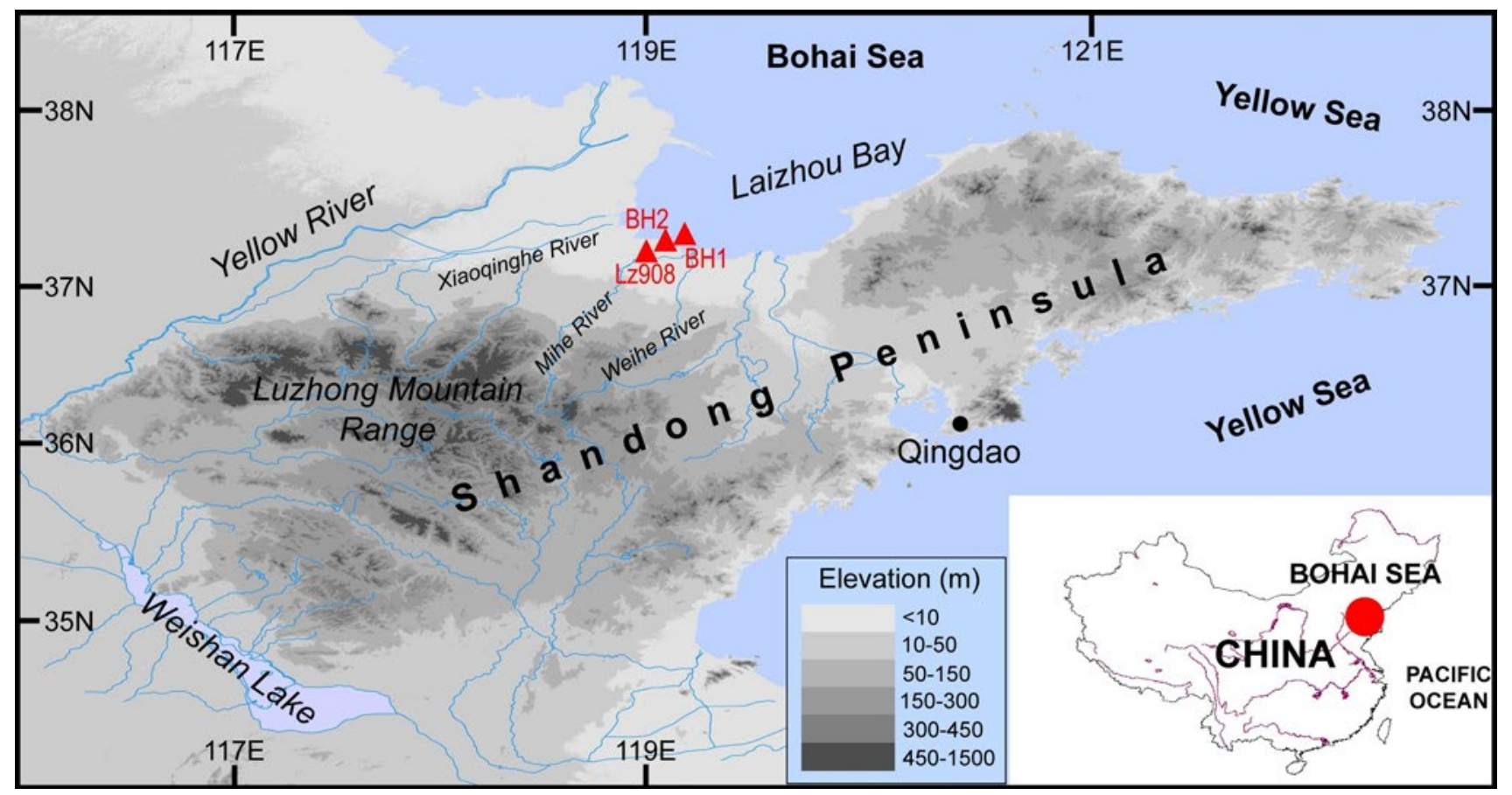

Fig. 1. Location of the south Bohai Sea in China, Geographical settings and position of Lz908, BH1 and BH2 cores ( $\mathbf{\Delta})$.

eter of $110 \mathrm{~mm}$ and the recovery rate is $75 \%$. Borehole BH1 $\left(37^{\circ} 17^{\prime} \mathrm{N}, 119^{\circ} 06^{\prime} \mathrm{E}\right.$, water depth $\left.-4 \mathrm{~m}\right)$ was drilled in the winter of 2008. The core's length was $198.8 \mathrm{~m}$ and the recovery rate was $90 \%$. Borehole $\mathrm{BH} 2\left(37^{\circ} 10^{\prime} \mathrm{N}\right.$, $119^{\circ} 04^{\prime} \mathrm{E}$, elevation $3 \mathrm{~m}$ ) was drilled in the spring of 2009. The drilling position was covered by seawater until the middle of last century. The core's length was $228.2 \mathrm{~m}$ and the recovery rate was $85 \%$. All of these samples were well dated (Yi et al., 2012a, 2012b) and displayed similar luminescence characters allowing testing the SGC method to OSL dating coastal sediments.

\section{Sample pre-treatment and measurement techniques}

\section{Lz908 core}

Nine OSL samples were taken by hammering metal cylinders of $2.5 \mathrm{~cm}$ (diameter) $\times 6 \mathrm{~cm}$ (length) horizontally into the core after being cut half. The samples were extracted under subdued red light and pretreated with $30 \% \mathrm{HCl}$ and $30 \% \mathrm{H}_{2} \mathrm{O}_{2}$ to remove the carbonates and organic material, respectively. Then the fine silt $(4-11 \mu \mathrm{m})$ was obtained using sedimentation procedures based on Stokes' Law. These polymineral fine grains were immersed in $\mathrm{H}_{2} \mathrm{SiF}_{6}(30 \%)$, for a week in an ultrasonic bath to obtain the fine-grained quartz component. The purity of prepared quartz was tested by the routine IR stimulation (Lai and Brückner, 2008), and then were mounted on the centre part with a diameter of $\sim 0.5 \mathrm{~cm}$. In our discs the grains are sparsely distributed and about 30000-50000 grains could be mounted according to Duller (2008) on stainless steel discs of a diameter of
$1 \mathrm{~cm}$. For $\mathrm{D}_{\mathrm{e}}$ determinations, we chose the pure quartz of fine silt $(4-11 \mu \mathrm{m})$ and followed the sensitivity-corrected multiple aliquot regenerative-dose protocol (MAR) developed by $\mathrm{Lu}$ et al. (2007) to determine the $\mathrm{D}_{\mathrm{e}} \mathrm{s}$. All measurements were performed using a Daybreak 2200 automated OSL reader in Qingdao Institute of Marine Geology, Chinese Geological Survey. Stimulation used blue LED $(\lambda=470 \pm 5 \mathrm{~nm})$ for $50 \mathrm{~s}$ at $125^{\circ} \mathrm{C}$. The OSL signal was detected by an EMI 9235QA photomultiplier tube and two $3 \mathrm{~mm}$ U-340 glass filters. The MAR conditions were: preheat at $260^{\circ} \mathrm{C}$ for $10 \mathrm{~s}$, cut-heat at $220^{\circ} \mathrm{C}$ for $10 \mathrm{~s}$; test doses (TD) of 1, 6, 10, 15, and 25 Gy were used for different samples, respectively; for each sample, one regeneration dose, ranging from 3 to $320 \mathrm{~Gy}$ according to the magnitude of the natural dose of that sample, were used for the construction of the growth curves.

\section{$\mathrm{BH} 1$ and $\mathrm{BH} 2$ cores}

OSL samples were taken by hammering metal cylinders of $5 \mathrm{~cm}$ (diameter) $\times 15 \mathrm{~cm}$ (length) vertically into the cores before being cut. Sample preparation was done under subdued red light in OSL laboratory. All samples were treated with $10 \% \mathrm{HCl}$ and $30 \% \mathrm{H}_{2} \mathrm{O}_{2}$ to remove carbonates and organics, respectively. We choose twentyfour samples of coarse-silt grain $(38-63 \mu \mathrm{m})$ and nine samples of fine-sand grain $(60-90 \mu \mathrm{m})$, when available, for OSL measurements. Grain-size fractions of 38-63 $\mu \mathrm{m}$ and $63-90 \mu \mathrm{m}$ were sieved. Quartz fraction of silty grains $(38-63 \mu \mathrm{m})$ was then treated with silica-saturated fluorosilicic acid $\left(\mathrm{H}_{2} \mathrm{SiF}_{6}\right)$ for about two weeks (Berger et al., 1980; Roberts et al., 2003) to remove feldspars. For fine- 
sand grains $(63-90 \mu \mathrm{m})$, we used hydrofluoric acid (HF) for 45-60 minutes to remove feldspars. The purity of prepared quartz was tested by the routine IR stimulation (Lai and Brückner, 2008). The quartz grains were then mounted on the centre part with a diameter of $\sim 0.5 \mathrm{~cm}$. In our discs the grains are sparsely distributed and about 3000-5000 and 300-500 grains for silty and fine-sandy quartz, respectively, could be mounted according to Duller (2008) on stainless steel discs of a diameter of 1 $\mathrm{cm}$.

OSL measurements were carried out using a Risø DA-20 automated TL/OSL system at the Luminescence Dating Laboratory of Qinghai Institute of Salt Lakes, CAS. Stimulation used blue LED $(\lambda=470 \pm 20 \mathrm{~nm})$ for $40 \mathrm{~s}$ at $130{ }^{\circ} \mathrm{C} .90 \%$ diode power was used. OSL signal was detected using a 9235QA photomultiplier tube through a $7.5 \mathrm{~mm}$ thick Hoya U-340 detection filter.

$\mathrm{D}_{\mathrm{e}} \mathrm{s}$ were determined using the SAR protocol method (Murray and Wintle, 2000). To select an appropriate preheat temperature for $\mathrm{D}_{\mathrm{e}}$ determination, preheat plateau test was conducted for two samples, $\mathrm{BH} 1-3 \mathrm{~B}$ and $\mathrm{BH} 2-$ 16. Preheat temperatures from 220 to $300^{\circ} \mathrm{C}$ (for $10 \mathrm{~s}$ ) with an interval of $20^{\circ} \mathrm{C}$ were tested, using a cut-heat of $220^{\circ} \mathrm{C}$ for $10 \mathrm{~s}$. A good preheat plateau was observed from 220 to $280^{\circ} \mathrm{C}$ for the two samples. So, a preheat temperature of $260^{\circ} \mathrm{C}$ was selected for $\mathrm{D}_{\mathrm{e}}$ determination. These two samples were also taken for dose recovery test. The ratios of the given doses to the measured doses were $0.95 \pm 0.03$ and $0.99 \pm 0.02$, respectively. This result suggested that the SAR procedure is able to recover a laboratory dose. Thus, preheat was chosen to be at $260^{\circ} \mathrm{C}$ for 10 seconds and cut-heat at $220^{\circ} \mathrm{C}$ for $10 \mathrm{~s}$. OSL signals from the first $0.64 \mathrm{~s}$ stimulation were integrated for growth curve construction after background subtraction. For each sample, six or four regeneration doses, ranging from 0 to $600 \mathrm{~Gy}$, were used for the construction of the growth curves, whose test dose was set as $11.1 \mathrm{~Gy}$ for all samples. All aliquots satisfied the prerequisite that the recycling ratio is to be within the range of 0.9-1.1.

\section{RESULTS AND DISCUSSION}

According to Roberts and Duller (2004), the SGC process could be described as follows: (1) A luminescence signal $\left(\mathrm{L}_{\mathrm{x}}\right)$ is normalized using a test-dose response $\left(\mathrm{T}_{\mathrm{x}}\right)$; (2) The normalized luminescence signal $\left(\mathrm{L}_{\mathrm{x}} / \mathrm{T}_{\mathrm{x}}\right)$ is multiplied by the test dose $\left(\mathrm{T}_{\mathrm{D}}\right)$; (3) An SGC from the regenerative dose $\left(R_{D}\right)$ is fit to the standardized luminescence signal, i.e. $\left(\left(\mathrm{L}_{\mathrm{x}} / \mathrm{T}_{\mathrm{x}}\right) * \mathrm{~T}_{\mathrm{D}}\right)$; (4) The $\mathrm{D}_{\mathrm{e}}$ of the sample is determined based only on measurements of the normalized natural luminescence signal $\left(\left(\mathrm{L}_{\mathrm{n}} / \mathrm{T}_{\mathrm{n}}\right) * \mathrm{~T}_{\mathrm{D}}\right)$. The shape of fitting formula can be expressed as an exponential form (e.g. Burbidge et al., 2004; Roberts and Duller, 2004; Stevens et al., 2007; Hong and Choi, 2008; Telfer et al., 2008) or as an exponential form plus a linear component (e.g. Lai, 2006; Lai et al., 2007; Long et al., 2010;
Yang et al., 2011). An exponential plus linear form is described as follows:

$Y=k \times\left(1-e^{-\frac{X}{D_{o}}}\right)+c \times X+d$

Here

$Y=\frac{L_{X}}{T_{X}} \times T_{D}$

is standardized OSL, $\mathrm{X}$ is the regenerative dose, $k$ is the standardized OSL intensity at saturation level for exponential growth part, $\mathrm{D}_{0}$ is the characteristic dose at which the slope of growth curve (exponential part) is equal to $1 / \mathrm{e}$ of the initial value, and $\mathrm{c}$ and $\mathrm{d}$ are constants defining the linear component. We choose Eq. 3.1 as the target function for testing of the SGC method.

The sedimentary processes that the grains experienced are important factors that affect grains' luminescence characteristics. For instance, the characteristics of loess, such as its medium-to-long transport distances, suggest that any previous luminescence signal should be removed prior to deposition, making it an ideal material for the testing of luminescence techniques (Roberts, 2008). However, the complex hydrodynamics of marine and coastal sediments can result in large errors in estimations of luminescence ages (Jacobs, 2008). Grains that settled in different positions also experience different sedimentary processes. As stated by Chen et al. (in press), in the southern Bohai Sea, silty grains are suspended and move seaward whereas fine-sand grains are trapped in situ. For same grains, sedimentary alternations were mainly between deltaic, estuarine and tidal plain systems (Xue and Ding, 2008). A few tens of sandy quartz grains can significantly vary dose responses (Duller, 2008). We therefore tested the suitability of SGC in dating coastal sediments starting with comparisons of the $\mathrm{D}_{\mathrm{e}} \mathrm{s}$ of aliquots, of samples, and of cores.

\section{SGC of fine-silt (4-11 $\mu \mathrm{m})$ quartz extracted from the Lz908 core}

\section{Standardized growth curve construction for fine-silt quartz}

Because of the dependence of the standardized dose response upon the size of test dose (Shen and Mauz, 2011), a standardized OSL obtained for fine-silt quartz was first converted to an equivalent standardized OSL, according to the calibration developed in Shen and Mauz (2011). Combining the data from all nine samples, an SGC can be produced by following the steps proposed by Roberts and Duller (2004) (Fig. 2):

$Y=37.186 \times\left(1-e^{\frac{X}{56}}\right)+0.134 \times X+0.754$ 

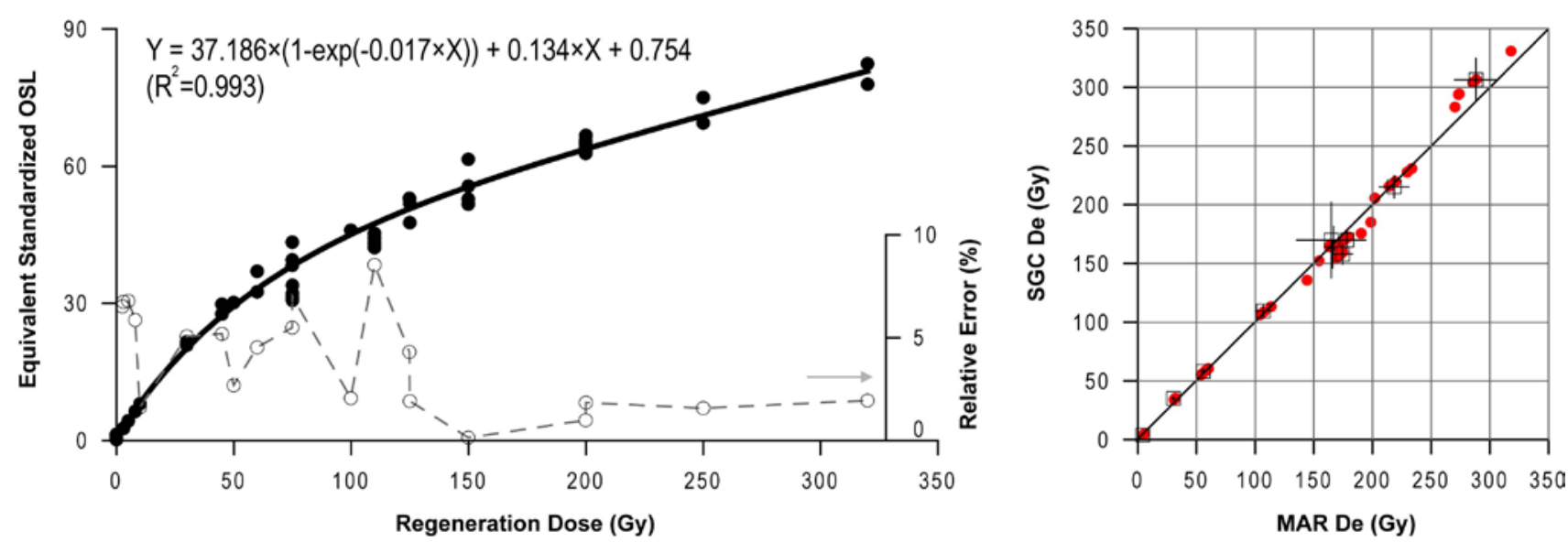

Fig. 2. SGC constructed using the fine-silt quartz of nine samples from Lz908 core (left panel). Also shown is the fitting equation, together with $R^{2}$ value. The recuperation is negligible for these samples, as the fitting line almost goes through the original point. In all cases, the error bar is smaller than the symbol (right-hand y-axis). Comparison of $D_{e}$ s between MAR and SGC methods is displayed in right panel. Solid cycles in the right panel indicate individual $D_{e} S$.

The explained variance $\mathrm{R}^{2}=0.990$, the freedomadjusted explained variance $\mathrm{R}_{\text {adj }}^{2}=0.993$, the standard deviation of the regression s.e. $=2.246$, and all coefficients are significant at $p<0.01$.

\section{Comparison between $S G C_{\text {fine-silt }}$ and MAR}

Because the individual growth curve is constructed from all aliquots and because the fitting domain of a given SGC is exactly same as the individual growth curve produced using an MAR protocol, we cannot directly compare the $\mathrm{D}_{\mathrm{e}} \mathrm{s}$ of $\mathrm{SGC}_{\text {fine-silt }}$ and individual growth curves. For this reason, we developed a substituted process to assess the applicability of SGC: (1) An $\mathrm{SGC}_{\mathrm{i}}$ is determined using eight out of the nine samples; (2) This $\mathrm{SGC}_{\mathrm{i}}$ is used to estimate the $\mathrm{D}_{\mathrm{e}} \mathrm{s}$ of the remaining sample; (3) The $\mathrm{D}_{\mathrm{e}}$ s produced using the MAR and SGC methods are compared; (4) These steps are repeated nine times, leaving a different sample out of step (1) each time.

A graphic comparison between $D_{e} s$ produced using the SGC and MAR methods is displayed in Fig. 2. The averaged $D_{e} s$ of five samples were found to match each other well. The SGC method was found to produce smaller $D_{e}$ values than the MAR method for three samples and larger $\mathrm{D}_{\mathrm{e}}$ values for two samples. The standard deviation values of SGC method were all significantly smaller than those of the MAR method.

A statistical comparison between $\mathrm{D}_{\mathrm{e}}$ s from $\mathrm{SGC}$ and MAR methods was conducted using one-way analysis of variance (ANOVA) which is used to test the hypothesis that several means are equal (Kleinbaum et al., 1997). Herein, the dependent variables are $\mathrm{D}_{\mathrm{e}} \mathrm{s}$, and the singlefactor (independent) variable is the method, SGC or MAR. Results are displayed in Table S1. They indicate that the $D_{e} s$ of most of the samples were not significantly different between the two methods. It can be concluded that, for 4-11 $\mu \mathrm{m}$ quartz samples from Lz908 core, $\mathrm{D}_{\mathrm{e}} \mathrm{s}$ calculated using the SGC method are statistically the same as those calculated using the MAR method, and SGC is suitable for use in the OSL dating of fine-silt quartz OSL dating.

Fine-sand $(63-90 \mu \mathrm{m})$ samples processed using the SAR protocol

\section{Comparison of growth curves of individual aliquots of the same sample}

Figs. 3A-D shows individual growth curves of six aliquots for samples BH1-6B, BH1-14B, BH2-5 and BH215 , respectively. The growth of the normalized OSL signal with regeneration dose is very similar across all six aliquots within a sample. This pattern was observed for all samples dated using the SAR protocol in this study.

\section{Comparison of growth curves of individual samples from the same core}

The average growth curves of all nine fine-sand samples from $\mathrm{BH} 1$ and $\mathrm{BH} 2$ cores are shown in Figs. 3E-F, respectively. The normalized OSL signal levels for a given regeneration dose are identical, with small standard errors. This implies that the samples from same core shared the same dose-response curve.

\section{Comparison of growth curves from two cores}

In order to examine the statistical fidelity of a SGC in different dataset, two average growth curves from $\mathrm{BH} 1$ and $\mathrm{BH} 2$ cores were estimated. Results are shown in Figs. 3E and F, respectively. Each curve was then used to estimate the $\mathrm{D}_{\mathrm{e}}$ of the other curve. The parameters of these two growth curves were very similar, and the $D_{e}$ offsets were below $20 \%$, suggesting the independence of the SGC method on different cores. 

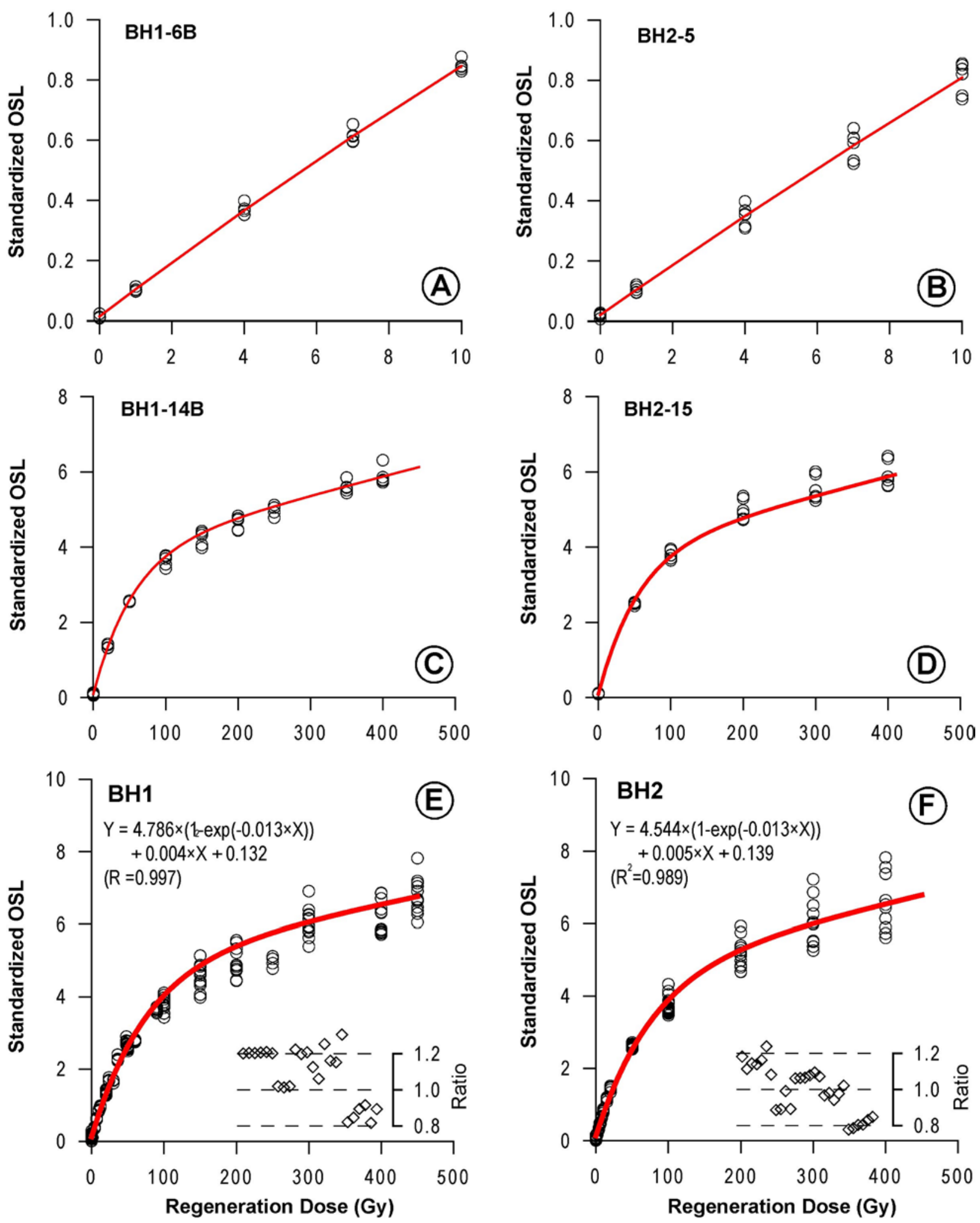

Fig. 3. (A-D) Growth curves of six aliquots for sample BH1-6B, BH2-5, BH1-14B and BH2-15, respectively. The bold lines represent the average curves of each sample. (E-F) Average growth curves (bold lines) of all $\mathrm{BH} 1$ and $\mathrm{BH} 2$ samples, respectively, estimated from averaging standardized OSL data within samples. Inserts in $E$ and F show ratios between $D_{e}$ s based SAR and SGC methods: (1) Estimate a SGC based on BH1 dataset, and then estimate $D_{e} S$ of $B H 2$ dataset. The results are displayed in $E$. (2) Estimate a SGC based on $B H 2$ dataset, and then estimate $D_{e} S$ of $B H 1$ dataset. The results are displayed in F. Two equations are displayed in figures, indicating similarity of growth curves between cores. $D_{e}$ offsets are smaller than $20 \%$, suggesting independence of SGC method on different cores. 


\section{Standardized growth curve construction for fine-sand quartz}

The comparisons of growth curves in samples, in cores and between cores described above demonstrated that it is possible to construct a regional SGC for finesand quartz. An SGC was estimated by combining the data from all nine samples as below (Fig. 4):

$$
Y=4.286 \times\left(1-e^{-\frac{X}{63}}\right)+0.005 \times X+0.106
$$

The explained variance $\mathrm{R}^{2}=0.998$, the freedomadjusted explained variance $\mathrm{R}^{2}$ adj $=0.997$, the standard deviation of the regression s.e. $=0.110$, and all coefficients are significant at $p<0.01$.

As shown, all the regeneration dose points conform closely to the fitting line. The constant, here 0.106 , implies that the recuperation for these samples is negligible. This shows that the construction of the $\mathrm{SGC}_{\text {fine-sand }}$ was acceptable.

\section{Comparison of $D_{e}$ s estimated using $S G C_{\text {fine-sand }}$ and $S A R$}

For evaluation, we used $\mathrm{SGC}_{\text {fine-sand }}$ to determine the $\mathrm{D}_{\mathrm{e}} \mathrm{s}$ of the nine samples of $\mathrm{BH} 1$ and $\mathrm{BH} 2$ cores. A graphic comparison between $\mathrm{D}_{\mathrm{e}} \mathrm{s}$ from $\mathrm{SGC}_{\text {fine-sand }}$ and $\mathrm{SAR}$ is shown in Fig. 4. The averaged $D_{\mathrm{e}} \mathrm{s}$ of the four samples matched each other closely. SGC produced smaller $D_{e}$ values than $S A R$ for three samples, and larger $D_{e}$ values for two samples. The standard deviations of the two methods were similar.

A statistical comparison between $\mathrm{D}_{\mathrm{e}} \mathrm{s}$ from $\mathrm{SGC}_{\text {fine-sand }}$ and SAR methods was conducted using the One-Way ANOVA. The results (Table S1) showed a significant difference in the two samples, specifically BH1-17B and $\mathrm{BH} 2-13$. When a few dozen quartz grains were measured, a significant dose response variation was observed (e.g.
Duller, 2008). This caused the differences in the $D_{\mathrm{e}} \mathrm{s}$ of these two samples. Because many studies showed that the uncertainties of dating coastal and marine sediments were significantly larger than those of dating other deposits (e.g. Jacobs, 2008), the observed difference could also be related to the sedimentary process. It can be concluded that an SGC can be used in determination of the $D_{e}$ values of fine-sand quartz, but a careful assessment is necessary in the dating of older sediments.

\section{Coarse-silt (38-63 $\mu \mathrm{m})$ samples processed using the SAR protocol}

\section{Comparison of growth curves of individual aliquots of the same sample}

Figs. 5A-D show the growth curves of BH1-3B, BH1$11 \mathrm{~A}, \mathrm{BH} 2-4 \mathrm{~B}$ and $\mathrm{BH} 2-16$, respectively. The growth of the normalized OSL signal with regeneration dose was found to be similar for all aliquots within a given sample. This pattern was seen for all samples which have been dated using the SAR protocol in this study.

\section{Comparison of growth curves of individual samples from same core and between cores}

Figs. 5E-F show average growth curves of all coarsesilt samples of the $\mathrm{BH} 1$ and $\mathrm{BH} 2$ cores, respectively. In SGC applications in fine-silt and fine-sand quartz grains, the offset between low- and high-dose samples was small (Figs. 2-4), but the offset was highly visible in coarse silty quartz grains (see insets of Figs. 5E-F).

To determine the dose boundary for the low- and high-dose samples, we created a scatter plot of regeneration dose changes against the ratio between $D_{e}$ based on the SAR and SGC methods (Fig. 6A). The figure shows that the ratio varied considerably when the dose was below 100 Gy and clustered around 1 when the dose
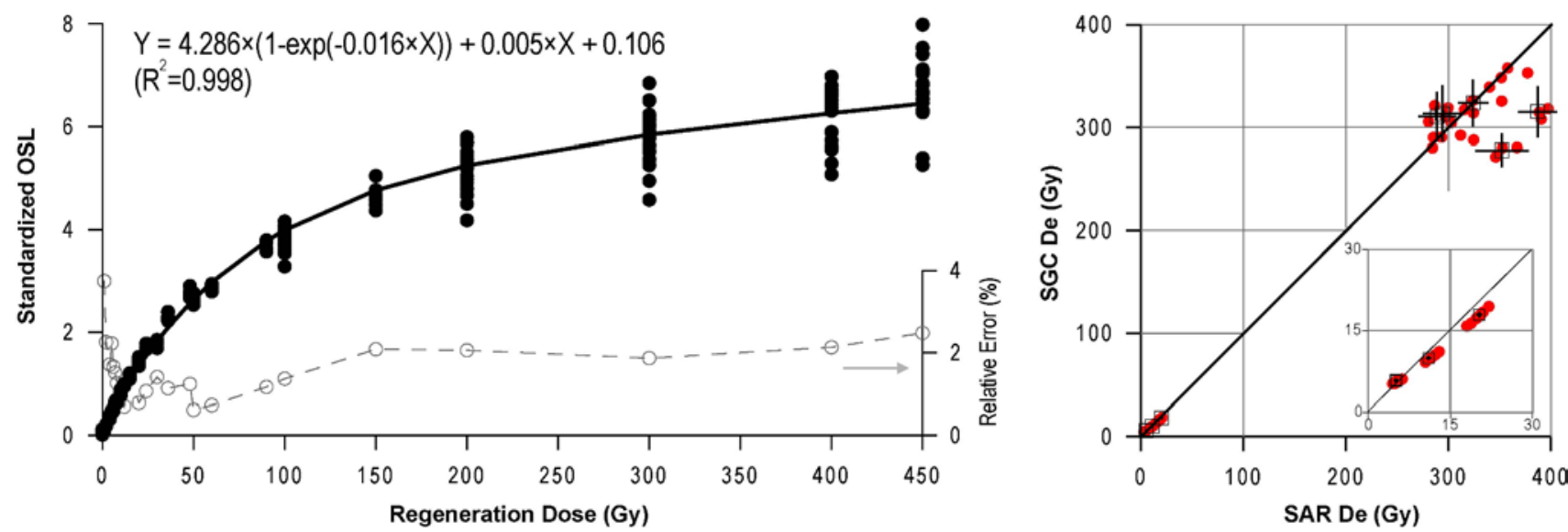

Fig. 4. The SGC constructed using the fine-sand quartz of nine samples from BH1\&BH2 cores, estimated from averaging standardized OSL data within samples (left panel). Also shown is the fitting equation of the SGC, together with $R^{2}$ value. The recuperation is negligible for these samples, as the fitting line almost goes through the original point. In all cases, the error bar is smaller than the symbol (right-hand y-axis). Comparison of $D_{e} s$ between SAR and SGC methods (right panel). Solid cycles in the right panel indicate individual $D_{e} S$. 

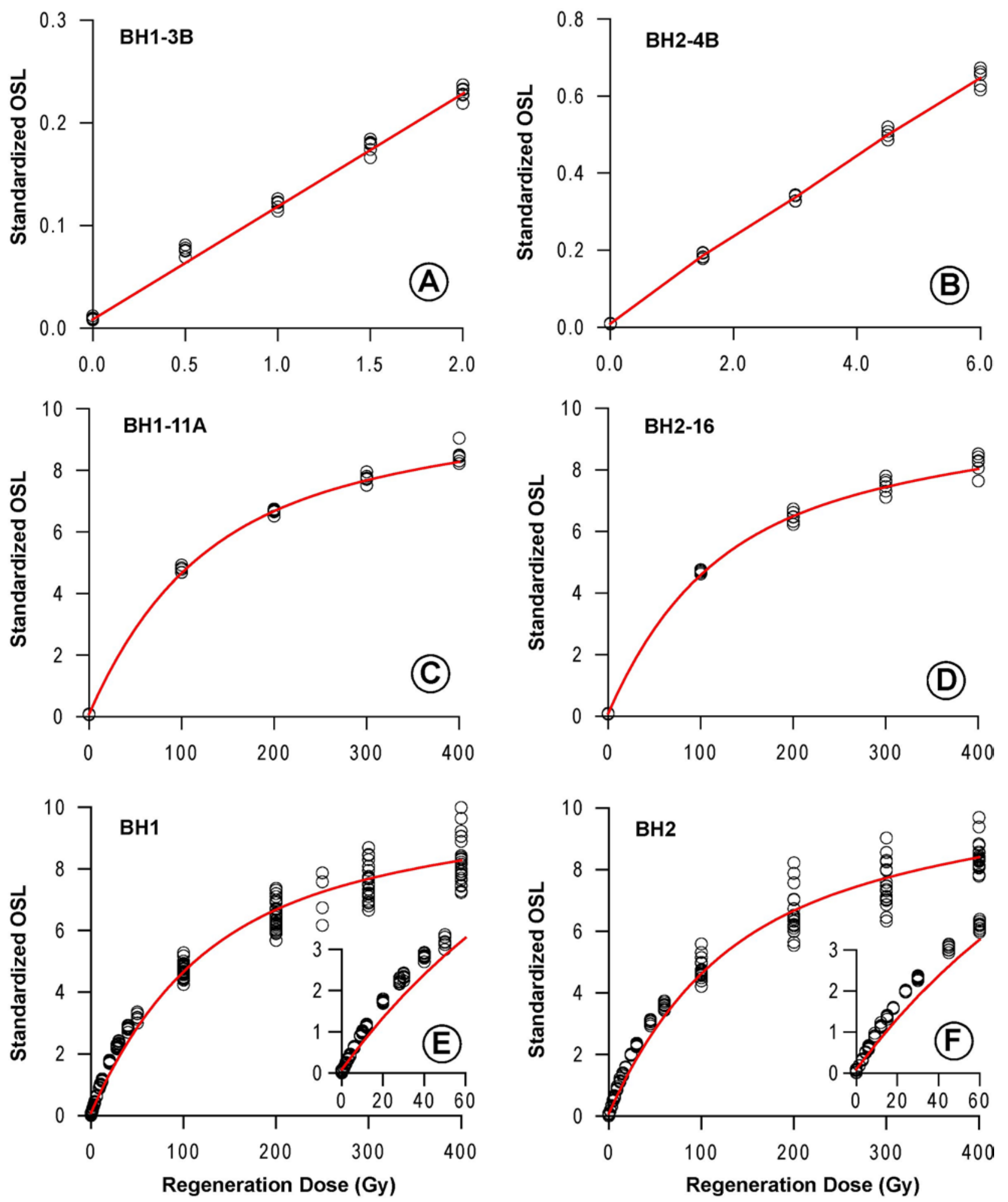

Fig. 5. (A-D) Growth curves of six aliquots for sample $B H 1-3 B, B H 2-4 B, B H 1-11 A$ and $B H 2-16$, respectively. The bold lines represent the average curves of each sample. (E-F) Average growth curves (bold lines) of all BH1 and BH2 samples, respectively, estimated averaging standardized OSL data within samples. The difference for relative low doses $(\leq 60 \mathrm{~Gy})$ is significantly under-estimated. 
was higher than $100 \mathrm{~Gy}$, indicating a clear boundary at $100 \mathrm{~Gy}$. Considering that there was no sample with a dose between 60 and $100 \mathrm{~Gy}$, we divided these twentyfour samples into two groups: low-dose $(\leq 60 \mathrm{~Gy})$ and high-dose ( $\geq 100 \mathrm{~Gy})$.

The results of several previous studies of SGC method showed different levels of performance for young and old samples and the boundary was found to vary with types of sediment. For instance, Telfer et al. (2008) found the boundary to be $50 \mathrm{~Gy}$, Yang et al. (2011) found it to be $80 \mathrm{~Gy}$, and it was found to be 270 Gy by Lai (2006).
However, regardless the type of sediment, the offset between low- and high-dose samples indicated differences in the luminescence characteristics of young and old samples. The cause of this difference can be sedimentary process or $\mathrm{D}_{\mathrm{e}}$ 's variation. Yi et al. (2012c) detailed four grain-size components of sediment in this area, classifying them as those whose modes were finer than $4,4.6-$ $12.5,23.4-63.3$ and $67.1-132.6 \mu \mathrm{m}$, respectively. They stated that the sedimentary process of the large two components did not change significantly. The offset between low- and high-dose coarse silty quartz could not have
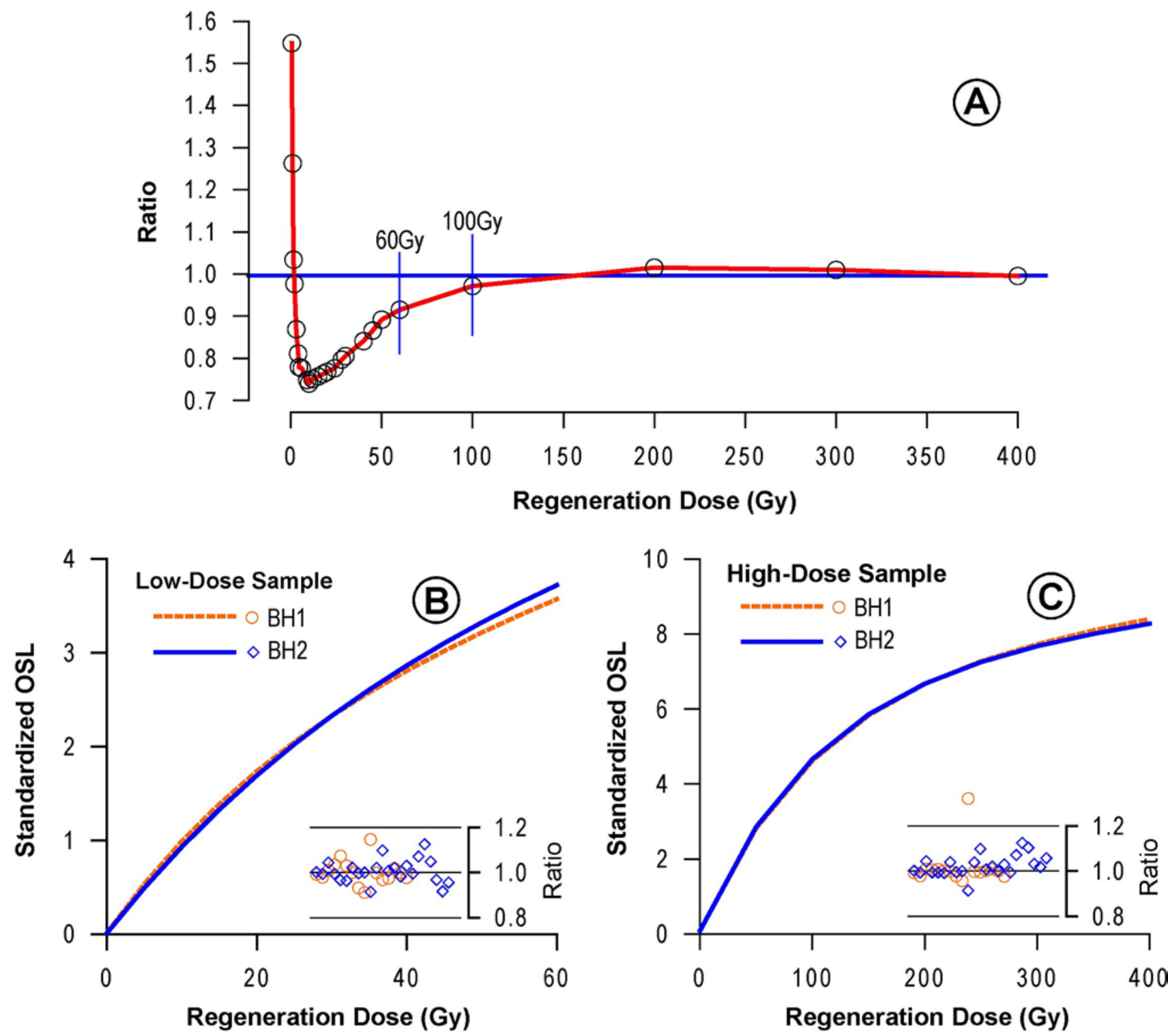

Fig. 6. A, Determination of the boundary for the low- and high-dose samples. The doses were firstly estimated using a combined dataset of all samples, then divided by the original data, and plotted against the original data. $B$ and $C$ are average growth curves of $B H 1 \& B H 2$ samples for low- and high-dose quartz, respectively, estimated from averaging standardized OSL data within samples. Inserts in $B$ and $C$ show ratios between $D_{e} S$ based SAR and SGC methods: (1) Estimate a SGC based on BH1 dataset, and then estimate $D_{e} S$ of BH2 dataset, displayed as circles in B and C; (2) Estimate a SGC based on BH2 dataset, and then estimate $D_{e}$ of $B H 1$ dataset, displayed as diamonds in $B$ and $C$. Two equations are displayed in figures, indicating similarity of growth curves between cores. $D_{e}$ offsets are smaller than $20 \%$, suggesting independence of SGC method on different cores. 
come from changes in the sedimentary process but rather from variation in $D_{\mathrm{e}}$. As shown in Figs. 2-5, the ascending trend in $\mathrm{D}_{\mathrm{e}}$ was dependent on the regeneration doses, which becomes significant in coarse silty quartz. This has been found in many previous studies (e.g. Lai et al., 2007; Long et al., 2010). According to Yi et al. (2012c) and Chen et al. (in press) the coarse silty grains are the most dynamics materials in sediment transport, the sedimentary processes of these grains were more complex than others and likely resulted in larger scatter. Because of contamination with heavy minerals (Lai et al., 2007), some grains might have low saturation doses and so create the low- and high-dose samples that share different dose-response curves.

In order to examine the statistical fidelity of a SGC in different dataset, four average growth curves from $\mathrm{BH} 1$ and $\mathrm{BH} 2$ cores were estimated, and they are shown in Figs. 6B and C, respectively. Each curve was then used to estimate the $D_{e}$ of the other curve. $D_{e}$ offsets were below $20 \%$, suggesting independence of SGC method on different cores. The growth curves of the $\mathrm{BH} 1$ and $\mathrm{BH} 2$ cores for low- and high-dose samples are all overlapping, indicating that it is possible to combine these two datasets for use in SGC applications.

\section{Standardized growth curve construction for coarse-silt quartz}

Two SGCs were developed by combining data from all twenty-four samples (Fig. 7):

1) For low-dose samples:

$$
Y=3.161 \times\left(1-e^{-\frac{X}{37}}\right)+0.018 \times X+0.032
$$

The explained variance $\mathrm{R}^{2}=0.999$, the freedomadjusted explained variance $\mathrm{R}^{2}$ adj $=0.998$, the standard deviation of the regression s.e. $=0.044$, and all coefficients were significant at $p<0.01$.

2) For high-dose samples:

$$
Y=6.940 \times\left(1-e^{-\frac{X}{111}}\right)+0.004 \times X+0.090
$$
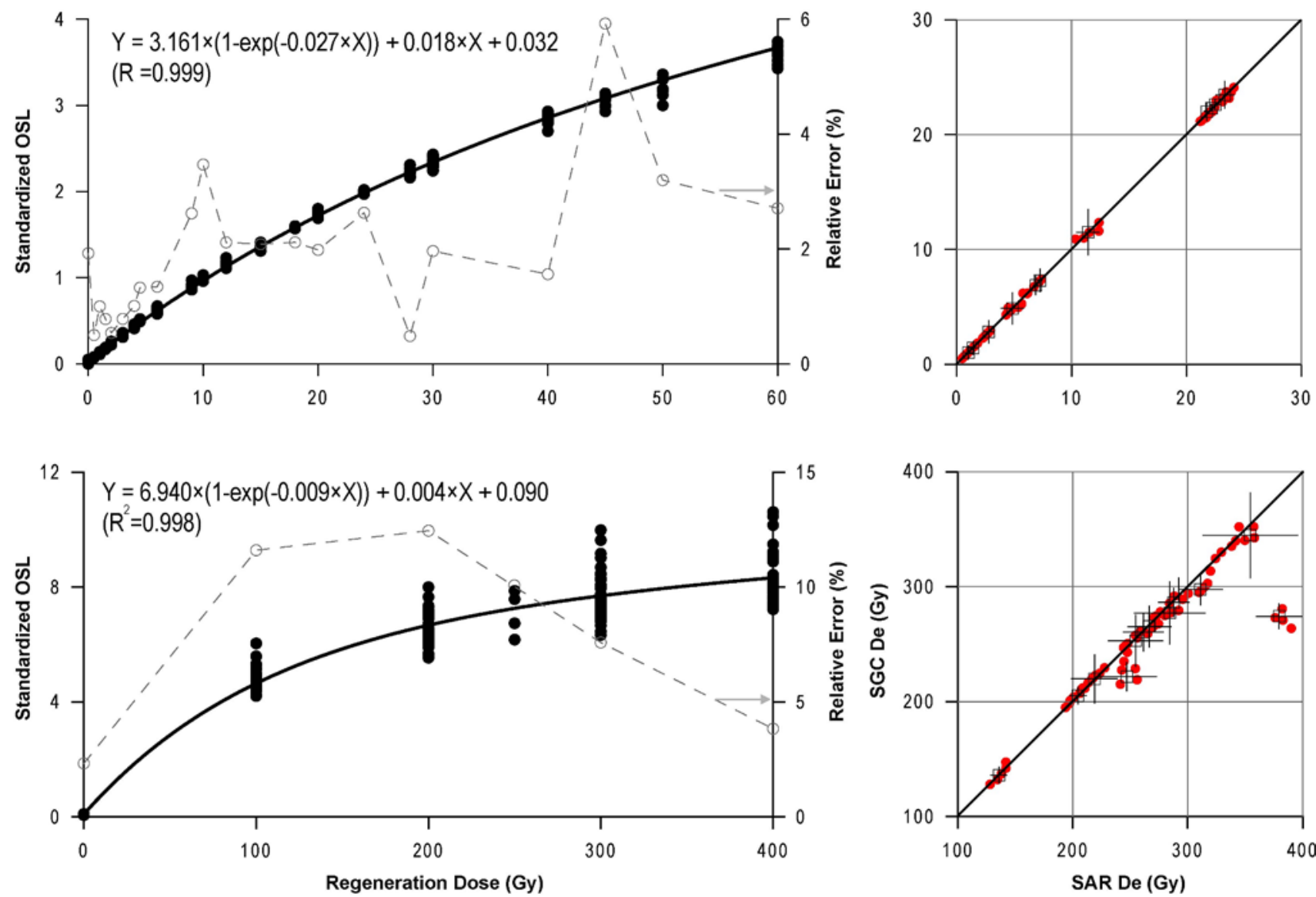

Fig. 7. The SGC constructed using the coarse-silt quartz of twenty-four samples from BH1\&BH2 cores (A\&C, left panel) for both low-dose (A, upper panel) and high-dose (C, bottom panel). Also shown are the fitting equations of SGC with $R^{2}$ values, estimated from averaging standardized OSL data within samples. The recuperation is negligible for these samples, as the fitting line almost goes through the original point. In all cases, the error bar is smaller than the symbol (right-hand y-axis). Comparison of $D_{e}$ s between $S A R$ and SGC methods (B\&D, right panel) for both low-dose (B, upper panel) and high-dose ( $D$, bottom panel). Solid cycles in the right panels indicate individual $D_{e} S$. 
The explained variance $\mathrm{R}^{2}=0.999$, the freedomadjusted explained variance $\mathrm{R}_{\text {adj }}^{2}=0.997$, the standard deviation of the regression s.e. $=0.161$, and all coefficients were significant at $p<0.01$.

As shown, all regeneration dose points stuck closely to the fitting line. The constants of 0.032 and $0.090 \mathrm{im}-$ plied that the recuperation for these samples was negligible. In this way, the construction of $\mathrm{SGC}_{\text {coarse-silt was }}$ found to be proper.

\section{Comparison of $D_{e} s$ calculated using $S G C_{\text {coarse-silt }}$ and SAR}

A graphic comparison between $\mathrm{D}_{\mathrm{e}} \mathrm{s}$ from $\mathrm{SGC}_{\text {coarse-silt }}$ and SAR is displayed in Fig. 7. All low-dose samples matched each other, but they all showed a much larger variance in $\mathrm{D}_{\mathrm{e}} \mathrm{s}$ from $\mathrm{SGC}_{\text {coarse-silt }}$ than from SAR. Highdose samples with doses under 300 Gy matched with each other, but some of the samples with doses over 300 Gy showed marked underestimation of in $D_{e}$ when $\mathrm{SGC}_{\text {coarse-silt }}$ was used. Statistical comparison between $\mathrm{D}_{\mathrm{e}} \mathrm{s}$ from $\mathrm{SGC}_{\text {coarse-silt }}$ and $\mathrm{SAR}$ methods was conducted using One-Way ANOVA. The results were displayed in Table S1. They indicated that only three samples, specifically BH1-15B, BH1-19A and BH2-17B, whose doses were all larger than 300 Gy had significantly different $D_{e} s$. This implied that most of $\mathrm{D}_{\mathrm{e}}$ s from SGC method were statistically similar to those produced using SAR.

\section{CONCLUSIONS}

Standardized growth curves have been shown to be reliable in estimation of $D_{e}$ values if a cautious and thorough approach is taken through the utilization of regional data sets (Telfer et al., 2008). The key points resulting from these experiments with SGCs are as follows: (1) For both the MAR and SAR OSL dating protocols, the SGC method was found to be applicable, providing reliable estimations of $\mathrm{D}_{\mathrm{e}}$. (2) Fine-sand quartz with different palaeodoses had approximately similar dose-response curves, but attention should be paid dating "old" sediments. (3) For coarse-silt quartz, the dose-response curves can be divided into two groups, low-dose ( $\leq 60 \mathrm{~Gy})$ and high-dose $(\geq 100 \mathrm{~Gy})$. Growth curves of low-dose quartz were similar, facilitating the use of SGC in $D_{e}$ estimations, but errors were large. For high-dose (100-300Gy) quartz, the SGC was also reliable but showed large amounts of uncertainty when $\mathrm{D}_{\mathrm{e}}$ was larger than $300 \mathrm{~Gy}$. We therefore suggest that SGC could be employed in the dating of coastal sediments with either MAR or SAR OSL protocols and either fine-silt, coarsesilt or fine-sand quartz.

\section{ACKNOWLEDGEMENTS}

The authors are grateful to Dr. G. Adamiec (the editor) and two anonymous reviewers for their constructive suggestion and comments, which have improved this manuscript. The authors also thank Qing Miao and Shunfeng Zhang for their help during drilling and sampling, and Biao Zhang for help during OSL experiments and for discussions. This research was supported by the China Postdoctoral Science Foundation (grant: 2012M520369), National Natural Science Foundation of China (grant: 41002125, 40906047, 40925012). National Basic Research Program of China (grant: 2012CB821900).

\section{APPENDIX}

The Table S1, the One-Way ANOVA results of estimated $\mathrm{D}_{\mathrm{e}} \mathrm{s}$ between MAR/SAR and SGC methods from various quartz of three cores drilled from the south Bohai Sea, China, is provided as Supplementary Material and is available in electronic version of this article at http://dx.doi.org/10.2478/s13386-013-0103-z.

\section{REFERENCES}

Berger GW, Mulhern PJ and Huntley DJ, 1980. Isolation of Silt-Sized Quartz Grains from Sediments. Ancient TL 11: 8-9.

Burbidge CI, Duller GAT and Roberts HM, 2004. De determination for young samples using the standardised OSL response of coarsegrain quartz. Radiation Measurements 41(3): 278-288, DOI 10.1016/j.radmeas.2005.06.038.

Chen F, Fan Y, Chun X, Madsen D, Oviatt C, Zhao H, Yang L and Sun Y, 2008. Preliminary research on Megalake Jilantai-Hetao in the arid areas of China during the Late Quaternary. Chinese Science Bulletin 53: 1725-1739.

Chen GQ, Yi L, Chen SL, Huang HJ, Liu YX, Xu YH and Cao JR, in press. Partitioning of grain-size components of estuarine sediments and its implication for sediment transport in the southwest of Laizhou Bay, China. Chinese Journal of Oceanology and Limnology, accepted manuscript.

Chen M, Chen JG and Wang JF, 1991. The evolution trend of swamping, salting and desertization along the coast of Bohai Sea and its relationship to global change. Quaternary Sciences 11: 113-122. (In Chinese with English abstract).

Duller GAT, 2008. Single-grain optical dating of Quaternary sediments: why aliquot size matters in luminescence dating. Boreas 37(4): 589-612, DOI 10.1111/j.1502-3885.2008.00051.x.

Gao WM, Li JL and Sun ZY, 1980. Formation and evolution of the YiShu continental rift. Seismology and Geology 2: 11-18.

Han DL, 2001. Geochemistry of Core E in the Laizhou Bay since late stage of Middle Pleistocene. Acta Oceanologica Sinica 23: 79-85 (in Chinese with English abstract).

Hong DG and Choi JH, 2008. Investigations on standardized growth curve (SGC) procedure for optical dating of heated quartz. Journal of Radioanalytical and Nuclear Chemistry 275(3): 613-617, DOI 10.1007/s10967-007-7076-4.

Jacobs Z, 2008. Luminescence chronologies for coastal and marine sediments. Boreas 37(4): 508-535, DOI 10.1111/j.15023885.2008.00054.x.

Kang SG, Wang XL and Lu YC, 2012. The estimation of basic experimental parameters in the fine-grained quartz multiple-aliquot regenerative-dose OSL dating of Chinese loess. Radiation Measurements 47(9): 674-681, DOI 10.1016/j.radmeas.2012.01.009.

Kleinbaum D, Kupper L, Muller K and Nizam A, 1997. Applied Regression Analysis and Other Multivariable Methods (3rd Ed). Pacific Grove: Duxbury Press.

Lai Z and Brückner H, 2008. Effects of feldspar contamination on Equivalent Dose and the shape of growth curve for OSL of siltsized quartz extracted from chinese loess. Geochronometria 30: 49-53, DOI 10.2478/v10003-008-0010-0. 
Lai ZP, 2006. Testing the use of an OSL standardized growth curve (SGC) for De determination on quartz from the Chinese Loess Plateau. Radiation Measurements 41(1): 9-16, DOI 10.1016/j.radmeas.2005.06.031.

Lai ZP, Brückner H, Zöller L and Fülling A, 2007. Existence of a common growth curve for silt-sized quartz OSL of loess from different continents. Radiation Measurements 42(9): 1432-1440, DOI 10.1016/j.radmeas.2007.08.006.

Long H, Lai ZP, Fan QS, Sun YJ and Liu XJ, 2010. Application of a quartz OSL standardised growth curve for De determination up to $400 \mathrm{~Gy}$ for lacustrine sediments from the Qaidam Basin of the Qinghai-Tibetan. Quaternary Geochronology 5(2-3): 212-217, DOI 10.1016/j.quageo.2009.05.005.

Lu YC, Wang XL and Wintle AG, 2007. A new OSL chronology for dust accumulation in the last $130,000 \mathrm{yr}$ for the Chinese Loess Plateau. Quaternary Research 67(1): 152-160, DOI 10.1016/j.yqres.2006.08.003.

Meng Q, Han M, Zhao M and Jiang A, 1999. A preliminary study of the Mihe River alluvial diluvial fan and the palaeochannels. Journal of Shandong Normal University (Natural Science) 14(1): 46-50 (in Chinese with English abstract).

Murray AS and Wintle AG, 2000. Luminescence dating of quartz using an improved single-aliquot regenerative-dose protocol. Radiation Measurements 32(1): 57-73, DOI 10.1016/S1350-4487(99)00253$\mathrm{X}$.

Murray AS and Olley JM, 2002. Precision and accuracy in the optically stimulated luminescence dating of sedimentary quartz: a status review. Geochronometria 21: 1-16.

Roberts HM, 2008. The development and application of luminescence dating to loess deposits: a perspective on the past, present and future. Boreas 37(4): 483-507, DOI $10.1111 / \mathrm{j} .1502-$ 3885.2008.00057.x.

Roberts HM and Duller GAT, 2004. Standardised growthcurves for optical dating of sediment using multiple-grain aliquots. Radiation

Measurements $38(2):$
10.1016/j.radmeas.2003.10.001.

Roberts HM, Muhs DR, Wintle AG, Duller GAT and Bettis EA, 2003. Unprecedented last-glacial mass accumulation rates determined by luminescence dating of loess from western Nebraska. Quaternary Research 59(3): 411-419, DOI 10.1016/S0033-5894(03)00040-1.

Shen ZX and Mauz B, 2011. Estimating the equivalent dose of late Pleistocene fine silt quartz from the Lower Mississippi Valley using a standardized OSL growth curve. Radiation Measurements 46(8): 649-654, DOI 10.1016/j.radmeas.2011.05.060.

Stevens T, Armitage SJ, Lu HY and Thomas DSG, 2007. Examining the potential of high sampling resolution OSL dating of Chinese loess. Quaternary Geochronology 2(1-4): 15-22, DOI 10.1016/j.quageo.2006.03.004.

Telfer MW, Bateman MD, Carr AS and Chase BM, 2008. Testing the applicability of a standardized growth curve (SGC) for quartz OSL dating: Kalahari dunes, South African coastal dunes and Florida dune cordons. Quaternary Geochronology 3(1-2): 137-142, DOI 10.1016/j.quageo.2007.08.001.
Wu S, Yu Z, Zou D and Zhang H, 2006. Structural features and Cenozoic evolution of the Tan-Lu Fault Zone in the Laizhou Bay, Bohai Sea. Marine Geology \& Quaternary Geology 26(6): 101-110 (in Chinese with English abstract).

Xu J, Ma Z, Cheng G, Long Z, Deng Q, Gao X, Zhang G, Cai D, Zhang $\mathrm{J}$ and Zhao J, 2005. Estimating times of Quaternary tectnoci episodes in the Bohai Sea based on geomorphic features of surrounding mountains areas. Quaternary Sciences 25: 700-710 (in Chinese with English abstract).

Xue C and Ding D, 2008. Weihe River-Mihe River Delta in South Coast of Bohai Sea, China: Sedimentary Sequence and Architecture. Scientia Geographica Sinica 28: 672-676 (in Chinese with English abstract).

Yang LH, Lai ZP, Long H and Zhang JR, 2011. Construction of a quartz OSL standardised growth curve (SGC) for aeolian samples from the Horqin dunefield in northeastern China. Geochronometria 38(4): 391-396, DOI 10.2478/s13386-011-0045-2.

Yi L, Yu H, Ortiz JD, Xu X, Chen S, Ge J, Hao Q, Yao J, Shi X and Peng S, 2012a. Late Quaternary linkage of sedimentary records to three astronomical rhythms and the Asian monsoon, inferred from a coastal borehole in the south Bohai Sea, China. Palaeogeography, Palaeoclimatology, Palaeoecology 329-310: 101-117, DOI 10.1016/j.palaeo.2012.02.020.

Yi L, Lai ZP, Yu HJ, Xu XY, Su Q, Yao J, Wang XL and Shi XF, 2012b. Chronologies of sedimentary changes in the south Bohai Sea, China: Constraints from luminescence and radiocarbon dating. Boreas, DOI 10.1111/j.1502-3885.2012.00271.x.

Yi L, Yu HJ, Ortiz JD, Xu XY, Qiang XK, Huang HJ, Shi XF and Deng CL, 2012c. A reconstruction of late Pleistocene relative sea level in the south Bohai Sea, China, based on sediment grain-size analysis. Sedimentary Geology 281: 88-100, DOI 10.1016/j.sedgeo.2012.08.007.

Yu HJ, Han DL, Liu X and Shan QM, 1999. Study on the disintegration of marine stratum in the northern shelf region of nearshore seas of China. Acta Oceanologica Sinica 21: 83-89 (In Chinese with English abstract).

Yu Z, Wu S, Zou D, Feng D and Zhao H, 2008. Seismic profiles across the middle Tan-Lu fault zone in Laizhou Bay, Bohai Sea, eastern China. Journal of Asian Earth Sciences 33: 383-394.

Zhang J-F, Huang W-W, Yuan B-Y, Fu R-Y and Zhou L-P, 2010. Optically stimulated luminescence dating of cave deposits at the Xiaogushan prehistoric site, northeastern China. Journal of Human Evolution 59(5): 514-524, DOI 10.1016/j.jhevol.2010.05.008.

Zhang Y, Dong S and Shi W, 2003. Cretaceous deformation history of the middle Tan-Lu fault zone in Shandong Province, eastern China. Tectonophysics 363(3-4): 243-258, DOI 10.1016/S00401951(03)00039-8.

Zhao S, 1991. China Shelf Sea desertization and its derived deposits during the last stage of late Pleistocene. Oceanologia and Liminologia Sinica 22: 285-293 (in Chinese).

Zhao S, 1995. Shelf Desertification. Ocean Press, China, Beijing (in Chinese). 